\title{
Human papilloma virus and breast cancer: the role of inflammation and viral expressed proteins
}

\author{
Niloofar Khodabandehlou', Shayan Mostafaei ${ }^{2,3}$, Ashkan Etemadi ${ }^{4}$, Amir Ghasemi $^{5}$, Mehrdad Payandeh ${ }^{6}$, \\ Shima Hadifar ${ }^{7}$, Amir Hossein Norooznezhad ${ }^{8}$, Anoshirvan Kazemnejad ${ }^{3}$ and Mohsen Moghoofei ${ }^{*^{*}}$
}

\begin{abstract}
Background: Breast cancer is currently the most common neoplasm diagnosed in women globally. There is a growing body of evidence to suggest that human papillomavirus (HPV) infection may play a key role in invasiveness of breast cancer. The aim of this study was to determine the presence of HPV in patients with breast cancer and its possible association with cancer progression.
\end{abstract}

Methods: Breast specimens were collected from 72 patients with breast cancer and 31 healthy controls. The presence of HPV was investigated by polymerase chain reaction (PCR) and genotyping was performed for positive cases. We also evaluated the viral factors such as E6, E2, and E7 in HPV positive cases. Enzyme-linked immunosorbent assay (ELISA (and Real-time PCR techniques were used to measure the expression level of anti-carcinogenic genes, such as p53, retinoblastoma $(R B)$, breast and ovarian cancer susceptibility gene (BRCA1, BRCA2) and inflammatory cytokines, including tumor necrosis factor a (TNF-a), transforming growth factor $\beta$ (TGF- $\beta$ ), nuclear factor-kB (NF-kB), and different interleukins [ILs] (IL-1,IL6, and IL-17).

Results: The HPV DNA was detected in $48.6 \%$ of breast cancer samples, whereas only $16.1 \%$ of controls were positive for HPV. We observed statistically significant differences between breast cancer patients and HPV presence $(P=0.003)$. HPV type 18 was the most prevalent virus genotype in patients. The expression of P53, RB, BRCA1, and BRCA2 were decreased in patients with HPV-positive breast cancer as compared to HPV-negative breast cancer and healthy controls. (All P-values were less than 0.05). The presence of the HPV was associated with increased inflammatory cytokines (IL-1, IL-6, IL-17, TGF- $\beta$, TNF-a, and NF-kB) and tumor progression.

Conclusion: The present study demonstrated that HPV infection may implicate in the development of some types of breast cancer.

Keywords: Breast cancer, Human papilloma virus, Risk factor, Tumor development, Inflammation

\section{Background}

Breast cancer is one of the most common cause of cancer deaths among women in both developing and developed countries. Moreover, mortality of this cancer is much more than both colorectal and lung cancers [1-3]. In the past two decades, the breast cancer rate has been increased worldwide with a considerable pace which has

\footnotetext{
* Correspondence: mohsenmoghoofei@yahoo.com

${ }^{9}$ Department of Microbiology, Faculty of Medicine, Kermanshah University of Medical Sciences, Sorkheh-Ligeh Blvd, P. O. Box: 6716777816, Kermanshah, Iran

Full list of author information is available at the end of the article
}

been suggested to be due to increasing known and/or unknown risk factors (RFs) of this cancer. A group of these RFs could be infectious agents which play a key role as carcinogens or promoters [4-6]. Recent studies have identified that some viruses, especially human papilloma virus (HPV), are among the RFs for the development of breast cancer, suggesting a strong association between HPV and breast cancer [7-10]. Many researches have been done on association between human papilloma virus (HPV) and cervical cancer and this issue is well accepted that HPV has the strong causal link with this cancer $[9,10]$. For the first time in 1992, the association between breast cancer

(c) The Author(s). 2019 Open Access This article is distributed under the terms of the Creative Commons Attribution 4.0 International License (http://creativecommons.org/licenses/by/4.0/), which permits unrestricted use, distribution, and reproduction in any medium, provided you give appropriate credit to the original author(s) and the source, provide a link to the Creative Commons license, and indicate if changes were made. The Creative Commons Public Domain Dedication waiver (http://creativecommons.org/publicdomain/zero/1.0/) applies to the data made available in this article, unless otherwise stated. 
and HPV was reported by Lonardo et al. [11]. The HPV is a non-enveloped DNA virus which belongs to the Papillomaviridae family with over 150 types [12]. It has been shown that at least a few types of HPV such as 6, 11, 15, 16,18 , and 33 are related to breast cancer $[13,14]$. The genome of such viruses are divided into three main segments; long control region (LCR), early region (E) which encoding $E 1, E 2, E 4-E 7$, and late region (L) consisting of $L 1$ and L2 [15]. E6 and E7 proteins, the oncoproteins, mainly act as stimulators of host cell proliferation [16]. E6 protein is a greatly important functional protein which interacts with p53 and BCL2 antagonist/killer (BAK 34) to increase the chromosomal instability and cellular resistance to apoptosis [17]. E7 protein interacts with retinoblastoma (RB) resulting in E2F release, a transcription factor which promotes cell proliferation. E7 up-regulates S-phase genes, cyclin A, and cyclin E but,contrarily, inhibits the cyclin-dependent kinase inhibitors such as the cyclin-dependent kinase inhibitor (WAF 1), known as p21, and Kinesin-like protein (KIP 1), known as p27 [16, 18]. Other equally important cellular factors, which interact with HPV proteins, are breast and ovarian cancer susceptibility gene-1 (BRCA1) and BRCA2. These genes are known for their tumor suppressor products, which prevent tumor development by repairing DNA damages. These proteins activate c-Jun $\mathrm{N}$-terminal kinase/stress-activated protein kinase (JNK/ SAPK) that eventually lead to apoptosis [19-21]. E7 and E6 interact with BRCA1 and antagonize several functions of BRCA1 [22].

Other factors such as inflammation have been shown to be involved in breast cancer progression. Chronic inflammation, which can be caused by persistent virus infections, is mediated by different cytokines and reactive oxygen nitrogen species (RONS). This chronic situation could suppress the antitumor immunity, promote metastasis development, and contribute to tumor progression [23-25]. Moreover, inflammation could enhance tumor progression which results in tissue remodeling, induction of the growth factors and angiogenesis [6]. Different cytokines such as transforming growth factors like beta (TGF- $\beta$ ), interleukin 1 (IL-1), IL-6, and IL-17 could stimulate breast cancer cell proliferation and/or invasion [26]. IL-6 is one of the inflammatory cytokines involved in tumor growth by evoking anti-apoptotic response and stimulating tumor development [27]. TGF- $\beta$ is a multifunctional cytokine involved in regulating many processes including differentiation, proliferation, and apoptosis of cancer cells. This cytokine seems to be the most extensively studied factor in breast cancer molecular studies [24]. During the inflammation, increased levels of IL-1 could induce breast cancer progression via angiogenesis, cell proliferation, and inhibition of apoptosis $[28,29]$. Tumor necrosis factor $\alpha$ (TNF- $\alpha)$, is another inflammatory cytokine expressed in high amounts and involved in breast cancer [24]. TNF- $\alpha$, IL- 6 and TGF- $\beta$ promote the production of IL- 17 which affects chronic inflammatory responses and thus tumor development [25]. NF- $\mathrm{kB}$ (nuclear factor kappa-light-chain-enhancer of activated B cells) is a protein which plays a critical role in regulating the immune response against infections. This feature seems to be the main linker between tumor development and inflammation [30]. Several studies have shown that NF-kB has a direct association with tumor initiation and cancer progression [31]. High levels of RONS in cancer tissue can significantly promote tumor development and metastasis [32, 33]. Chronic infection and inflammation are the cause of $20-25 \%$ of all human cancers [34]. Therefore, investigating the role of infection and inflammation in tumor initiation and development has been attracted intensive scientific interests in the fields of oncology and virology.

In the present case-control study, we aimed to determine the presence of HPV in breast cancer tissues and to evaluate the possible association between HPV infection and breast cancer development.

\section{Methods}

\section{Samples, methodology, and ethical standards}

This multi-central case control study was performed between January 2015 and March 2016 in the Kashani Hospital (Shahrekord, Iran) and Rasul-e Akram Hospital (Tehran, Iran). According to the inclusion and exclusion criteria, 72 breast specimens were collected, and all tissue samples were immediately snap frozen in liquid nitrogen and stored at $-80^{\circ} \mathrm{C}$. Inclusion criteria were defined as; women with approved histopathological (biopsy) evidence(s) of breast cancer, accessibility of fresh samples, native patients of Shahrekord and Tehran cities. Also, different parameters such as past or current medical history of chemotherapy and/or radiotherapy, being pregnant, biologic anti-cancer therapies, and systemic inflammatory disease such as rheumatoid arthritis were defined as exclusion criteria. No limitations in age, type of breast cancer, and tumor size or stage were considered for the patients. In addition, 31 normal breast tissue samples, obtained from breast reduction surgeries with normal histopathology results, were also examined as healthy controls (from both hospitals). All the controls were healthy women with no history of estrogen therapies, oral contraceptive consumption, cervical cancer, and smoking. For all the cases a carful breast examination was performed by an experienced surgeon. All the histopathology results were re-examined by two well experienced pathologists (double checking by M. Mogani and M. Khosravi) to certainly confirm the diagnosis. The stage of cancer, based on TNM system, was provided by consulting an expert cancer team consisting of an oncologist, a radiologist and a cancer surgeon. Tumor samples were classified histologically based 
on the World Health Organization (WHO) criteria [35]. Five paraffin-embedded pathologically proved cervical cancer samples were used as positive controls. All the participants signed a copy of consent form freely after verbal explanation of the aims and methods of this study according to their level of knowledge.

\section{HPV detection, genotyping and physical status}

The DNA extraction was performed using "QIAamp Tissue Kit" according to the manufacturer's instructions (QIAGEN, Hilden, Germany). A polymerase chain reaction (PCR)-based detection assay was employed to identify HPV, using primers for $L 1$ and $E 7$ genes [1]. Genotypes of HPV positive samples were determined by INNO-LiPA HPV Genotyping v2 test (Innogenetics, Ghent, Belgium) in strict accordance with the manufacturer's instructions. For this test, distilled water and paraffin sections without tissue were used as negative controls for PCR and DNA extraction, respectively. Moreover, isolated genotypes $(6,11,15,16,18$, and 33) of cervical cancer samples, in CIN3 and cervical cancer model, were used as positive controls for amplification. The serial dilutions of the full-length HPV genome was prepared to provide the standard control for copy number of $E 2$ and $E 6$ genes [36].

\section{Expression level of cellular and viral factors \\ E6}

Total RNA was extracted and purified from the tissue by using RNEasy Mini kit (QIAGEN, Hilden, Germany). Real-time PCR (RT-PCR) reactions were conducted with one step RT-PCR ${ }^{\circ}$ kits (QIAGEN, Hilden, Germany) according to the manufacturer's instructions. The used primers for amplifying the gene sequence for E6 were [37]:

Forward 5'-GCAATGTTTCAGGACCCACA-3' Reverse 5' -ACAGCATATGGATTCCCATCTC-3'.

\section{p53}

The level of p53 was assessedusing enzyme-linked immunosorbent assay (ELISA) using Abcam's p53 Simple Step ELISA ${ }^{\circ}$ Kit (Abcam, Cambridge, MA, USA) according to the manufacturer's instructions.

\section{E7}

For cDNA synthesis, 1 microgram of extracted total RNA was reverse transcribed using the QuantiNova Reverse Transcription ${ }^{\circ}$ Kit (QIAGEN, Hilden, Germany). The used primers and probe in $E 7$ gene amplification were [38]:

Forward primer: 5'-AAGTGTGACTCTACGCTTCGGTT-3'

Reverse primer: 5'-GCCCATTAACAGGTCTTCCAAA-3'

Probe: FAM-TGCGTACAAAGCACACACGTAGAC ATTCGTA-BHQ
$R B$

The expression level of RB gene was determined by $\mathrm{Hu}$ man Retinoblastoma ELISA ${ }^{\circ}$ kit (Sigma-Aldrich, Saint Louis, USA) according to the manufacture's protocol.

\section{E2}

Quantitative SYBR green TaqMan Universal PCR Master Mix $^{\circ}$ (QIAGEN, Germany) was used to monitor expression levels of E2 genes. The used primers in E2 gene amplification were [39]:

Forward primer: 5'-CTACGAATTCATGGAGACT CTTTGCCAACG-3

Reverse primer: 5'-GATAGAATTCTCATATAGA CATAAATCCAG-3'

\section{$B R C A 1$ and $B R C A 2$}

The expression level of BRCA1 and BRCA2 were measured by BRCA1 and BRCA2 ELISA Kits (Human) (MyBioSource, Inc. CA, USA) according to the manufacture's protocol.

\section{Cytokines and NF-kB evaluation}

The levels of IL-1, IL-6, IL-17 and NF-kB were measured using Human IL-6 ELISA ${ }^{\circ}$ Kit, Human IL-1 beta ELISA ${ }^{\circ}$ Kit, Human IL-17 ELISA ${ }^{\circ}$ Kit, and NFkB p65 Transcription Factor Assay Kit (Abcam, Cambridge, MA, USA), respectively, according to the manufacturer's instructions. Moreover, the amount of TGF- $\beta$ and TNF- $\alpha$ were measured by Human TGF-beta 1 Quantikine ELISA ${ }^{\bullet}$ Kit (Minneapolis, MN, USA) and Human TNF Alpha PicoKine $^{\mathrm{mt}}$ ELISA Kit (Boster Biological Technology, Pleasanton CA, USA), respectively, according to the manufacturer's instructions.

\section{Reactive oxygen species and reactive nitrogen species}

The RONS level was assessed by OxiSelect ${ }^{\mathrm{tm}}$ Intracellular ROS/RNS Assay kit (Cell Biolabs, Inc., San Diego, CA), following the protocol.

\section{Statistical methods}

Normality test was performed using Kolmogorov-Smirnov test for continuous variables. The two-independent samples t-test (Mann-Whitney non-parametric test) was conducted to compare the central tendency (e.g. mean for normal and median for non-normal gene expression) of gene expressions in such two groups. Correlation analysis was also carried outby Eta-squared coefficient. To identify the linear dependencies between two sets of the variables, the Canonical Correlation Analysis (CCA) was applied. Generalized linear model (logistic regression) was used to recognize the association between the presence of HPV and breast cancer. Moreover, for this test odds ratio (OR) as the effect size with $95 \%$ confidence intervals $(95 \% \mathrm{CI})$ was measured. False discovery rate 
was corrected by Benjamini-Hochberg approach for multiple comparisons. All data were finally analyzed using IBM SPSS version 21.0 (SPSS, Chicago, IL, USA) and GraphPad Prism version 6 (La Jolla, CA, USA). Any $P$-value less than 0.05 were considered statistically significant.

\section{Results}

In this study, 72 female breast cancer cases, including 9 (12.5\%), 20 (27.8\%), 32 (44.4\%), 3 (4.2\%), and 8 (11.1\%) patients with medullary carcinoma, invasive lobular carcinoma, invasive and in-situ ductal carcinoma, mucinous carcinoma, and tubular carcinoma were examined. The average age of the patients was $48.86 \pm 10.95$ years, ranging from 30 to 81 and for the controls it was $48.97 \pm$ 9.22 years old (ranged from 35 to 72 ), which was similar to the age of the patients $(P=0.76)$ (Table 1$)$.

HPV DNA was detected in 35 out of 72 patients (48.6\%) and 5 out of 31 healthy controls (16.1\%). The presence of HPV infection in the breast cancer control was found to be statistically significant $(P=0.003)$. The odds of breast cancer incidence in the HPV positive group was 4.92 (95\% C. I: 1.699-14.238), which was significantly more than HPV negative group. In the breast cancer group, five different genotypes were detected, namely, $18(N=16,22.2 \%), 16(N=13,18.1 \%), 33(N=4$, $5.6 \%), 6(\mathrm{~N}=1,1.4 \%)$, and $11(N=3,4.2 \%)$, while, in the healthy control group only two genotypes was observed;
$18(\mathrm{~N}=3,9.7 \%)$ and $16(N=2,6.5 \%)$ (Table 1$)$. The papillomavirus $E 2$ gene expression was absence in 30 cases of breast cancer group $(86 \%, P=0.006)$, therefore the genome of HPV E2 negative group was in an integrated form. However, the E2/E6 ratio was lower than 1 which indicates that HPV was in both episomal and integrated forms known as mixed form $(N$ $=5,14 \%)$. Also, the E2/E6 ratio in positive control group (5 cervical cancer samples), showed that only $20 \%$ (ration 1) was integrated and the other were episomal form, $80 \%$ (ratio 4$)(E 2 / E 6 \geq 1$ (. The $E 2 / E 6$ ratios and viral physical status in different cancer types and stages are compiled in Table 2. HPV DNA was detected in 16 patients (45.7\%) with ductal carcinoma (highest ratio), and no patients $(0 \%)$ with mucinous carcinoma (lowest ratio) was observed. Moreover, no significant association between histological types of breast cancer and HPV infection was detected $(P=$ 0.32 ). A significant difference was found in the incidence of HPV infection between cases and controls $(P=0.003)$. Also, the association of HPV genotypes and occurrence of breast cancer was statistically significant $(P=0.037)$. The frequency distribution of breast cancer stages and genotypes between HPV positives and HPV negatives controls were statistically different and the association of HPV with stages of breast cancer and genotypes was also significant $(P=0.045$ and $P<0.001$, respectively) (Table 3 ).

Table 1 Comparison of participants' characteristics between cases and controls

\begin{tabular}{|c|c|c|c|c|c|}
\hline Characteristics & & Breast cancer group $(N=72)$ & Healthy controls $(N=36)$ & $P$-value & OR $(95 \% \mathrm{Cl})$ \\
\hline Age (Year) & & $48.86 \pm 10.95$ & $48.97 \pm 9.22$ & 0.76 & - \\
\hline \multirow[t]{2}{*}{ HPV } & Presence & 35 (48.6\%) & $5(16.1 \%)$ & 0.003 & $4.92(1.70-14.24)$ \\
\hline & Absence & 37 (51.4\%) & $26(83.9 \%)$ & - & \\
\hline \multirow[t]{5}{*}{ Stage of Cancer } & $\mathrm{la}, \mathrm{lb}$ & $2(2.7 \%), 9(12.5 \%)$ & - & - & - \\
\hline & $\| \mathrm{a}, \mathrm{llb}$ & $20(27.8 \%), 19(26.3 \%)$ & - & - & - \\
\hline & IIla, IIlb, & $5(6.9 \%), 9(12.5 \%)$ & - & - & - \\
\hline & IIlc & $6(8.3 \%)$ & & & \\
\hline & IV & $2(2.7 \%)$ & - & - & - \\
\hline \multirow[t]{5}{*}{ Type of Cancer } & Ductal & $32(44.4 \%)$ & - & - & - \\
\hline & Lobular & $20(27.8 \%)$ & - & - & - \\
\hline & Medullary & $9(12.5 \%)$ & - & - & - \\
\hline & Tubular & $8(11.1 \%)$ & - & - & - \\
\hline & Mucinous & $3(4.2 \%)$ & - & - & - \\
\hline \multirow[t]{6}{*}{ Genotype } & Negative $(-)$ & 35 (48.6\%) & 26 (83.9\%) & 0.037 & - \\
\hline & HPV-18 & 16 (22.2\%) & 3 (9.7\%) & & \\
\hline & HPV-16 & 13 (18.1\%) & $2(6.5 \%)$ & & \\
\hline & HPV-33 & $4(5.6 \%)$ & - & & \\
\hline & HPV-11 & $3(4.2 \%)$ & - & & \\
\hline & HPV-6 & 1 (1.4\%) & - & & \\
\hline
\end{tabular}


Table 2 Physical status of HPV genome in cases and controls

\begin{tabular}{|c|c|c|c|c|c|}
\hline & Cases (\%) & & Controls (\%) & Total number & $P$-value \\
\hline \multirow[t]{7}{*}{ Integrated } & $30 / 35(86 \%)$ & & $1 / 5(20 \%)$ & $31 / 40(77.5 \%)$ & 0.006 \\
\hline & Stages: & Types: & & & \\
\hline & & Ductal $(n=11)$ & & & \\
\hline & I $(n=3)$ & Lobular $(n=4)$ & & & \\
\hline & $\|(n=3)$ & Medullary $(n=6)$ & & & \\
\hline & III $(n=9)$ & Tubular $(n=5)$ & & & \\
\hline & $\mathrm{IV}(n=15)$ & Mucinous $(n=4)$ & & & \\
\hline Episomal & - & & 4/5 (80\%) & $4 / 40(10 \%)$ & NA \\
\hline \multirow[t]{7}{*}{ Mixed } & $5 / 35(14 \%)$ & & - & $5 / 40(12.5 \%)$ & NA \\
\hline & Stages: & Types: & & & \\
\hline & I $(n=3)$ & Ductal $(\mathrm{n}=3)$ & & & \\
\hline & $\|(n=2)$ & Lobular $(n=0)$ & & & \\
\hline & III (n=0) & Medullary $(\mathrm{n}=1)$ & & & \\
\hline & IV $(n=0)$ & Tubular $(n=1)$ & & & \\
\hline & & Mucinous $(n=0)$ & & & \\
\hline
\end{tabular}

NA: Not applicable

The expression levels of p53 and RB was found to be reduced in HPV-positive breast cancer group compared to HPV-negative breast cancer and normal healthy controls $(P<0.001, P<0.001, P=0.033$, respectively) (Table 4$)$. In addition, there was a direct association between the decreased expression of the tumor suppressor genes ( $\mathrm{p} 53$, $\mathrm{RB}, B R C A 1$ and $B R C A 2$ ) and the progression stage of breast cancer. The results showed a significant negative association between expression of $E 6$ and p53 $(P=-0.743, \quad P<0.001)$, and similar association between the expression level of E7 and RB $(P=-0.805$, $P<0.001)$ was detected. According to CCA result, standardized canonical correlation coefficient between the expressions of inflammatory factors and viral proteins $(E 2$, $E 6$ and E7) were statistically significant $(P=0.692$ and $P=0.009)$. The expression levels of different inflammatory factors including IL- 1 , IL-6, IL-17, TGF- $\beta$, TNF- $\alpha$, NF- $\mathrm{kB}$, and RONS were statistically higher in HPV- positive

Table 3 Comparison of participants' characteristics between HPV positive and HPV negative groups in breast cancer cases

\begin{tabular}{|c|c|c|c|c|c|}
\hline \multicolumn{2}{|l|}{ Characteristics } & \multirow{2}{*}{$\begin{array}{l}\text { HPV+ } \\
48.00 \pm 11.11\end{array}$} & \multirow{2}{*}{$\begin{array}{l}\text { HPV- } \\
49.46 \pm 9.99\end{array}$} & \multirow{2}{*}{$\begin{array}{l}\text { P-value } \\
0.49\end{array}$} & \multirow{2}{*}{$\begin{array}{l}\text { OR }(95 \% \mathrm{Cl}) \\
-\end{array}$} \\
\hline Age (Year) & & & & & \\
\hline \multirow[t]{4}{*}{ Stage of Cancer } & I & $4(11.5 \%)$ & $7(18.9 \%)$ & Ref. & Ref. \\
\hline & $\|$ & 15 (42.8\%) & 24 (64.9\%) & 0.89 & $1.09(0.27-4.38)$ \\
\hline & III & $14(40 \%)$ & $6(16.2 \%)$ & 0.076 & $4.08(0.86-19.37)$ \\
\hline & IV & $2(5.7 \%)$ & 0 & 0.22 & NA \\
\hline \multirow[t]{5}{*}{ Type of Cancer } & Tubular & $5(14.3 \%)$ & $3(8.1 \%)$ & Ref. & Ref. \\
\hline & Ductal & $16(45.7 \%)$ & 16 (43.2\%) & 0.53 & $0.60(0.12-2.94)$ \\
\hline & Medullary & $4(11.4 \%)$ & $5(13.5 \%)$ & 0.46 & $0.48(0.06-3.35)$ \\
\hline & Lobular & $10(28.6 \%)$ & $10(27 \%)$ & 0.55 & $0.60(0.11-3.21)$ \\
\hline & Mucinous & 0 & $3(8.1 \%)$ & 0.15 & NA \\
\hline \multirow[t]{6}{*}{ Genotype } & Negative $(-)$ & 0 & 61 (96.8\%) & $<0.001$ & NA \\
\hline & HPV-18 & $18(45 \%)$ & $1(1.6 \%)$ & Ref. & Ref. \\
\hline & HPV-16 & 15 (37.5\%) & 0 & 0.58 & NA \\
\hline & HPV-33 & $4(10 \%)$ & 0 & 0.85 & NA \\
\hline & HPV-11 & $2(5 \%)$ & $1(1.6 \%)$ & 0.17 & $0.11(0.005-2.55)$ \\
\hline & HPV-6 & $1(2.5 \%)$ & 0 & 0.44 & NA \\
\hline
\end{tabular}


Table 4 Comparison of $R B$ and p53 expression levels between patients with breast cancer/ HPV positive groups and control samples/ HPV negative groups

\begin{tabular}{llllllll}
\hline Expression level & $\begin{array}{l}\text { Breast Cancer } \\
(N=72)\end{array}$ & $\begin{array}{l}\text { Control } \\
(N=31)\end{array}$ & Fold Change & $\begin{array}{l}\text { Adjusted } \\
P \text {-value }\end{array}$ & $\begin{array}{l}\text { HPV positive } \\
(N=40)\end{array}$ & $\begin{array}{l}\text { HPV negative } \\
(N=63)\end{array}$ & $\begin{array}{l}\text { Fold Change } \\
P \text {-value }\end{array}$ \\
\hline RB & $7.89 \pm 5.74$ & $10.65 \pm 6.39$ & 0.74 & 0.033 & $3.25 \pm 3.29$ & $12.19 \pm 4.67$ & 0.27 \\
$P 53$ & $9.81 \pm 7.51$ & $17.19 \pm 6.02$ & 0.57 & 0.001 & $5.30 \pm 4.46$ & $16.30 \pm 6.41$ & 0.33 \\
\hline
\end{tabular}

breast cancer patients than control samples and HPV-negative breast cancer patients. More details are presented in the Tables 5, 6 and Fig. 1.

\section{Discussion}

Breast cancer incidence and mortality rates are increasing markedly worldwide. This highlights the importance of identifying new RFs that are related to breast cancer development, in order to prevent or treat the disease [40]. Several factors are involved in initiation and development of cancer, among which are critically important biological carcinogens such as viral infections [41]. Viral infections have been shown to be involved in approximately $18-20 \%$ of cancers [40]. For example, HPV can induce inflammation due to some of its features including production of oncogenic proteins. This makes HPV a strong suspect for initiation and development of breast cancer [42].

In this study, among 72 evaluated samples, HPV DNA was found in $48.6 \%(n=35)$ of breast cancer samples. Several investigations have reported detecting HPV in breast cancer patients and its prevalence with a vast range from 4 to $86 \%$ [43]. A recent evaluation conducted by Sigaroodi et al. (2012, Iran) has shown a high frequency of HPV DNA in breast cancer patients (25.9\%) in contrast to the women with non-cancerous condition (2.4\%). According to their results, the HPV genotypes 16 and 18 with the accumulated prevalence of $53.34 \%$ in breast cancer patients were the most predominant. This study also showed that breast cancer in Iranian women was associated with HPV infection (OR 14.247, 95\% CI 1.558-130.284; $P=0.019$ ) [14]. Another investigation which performed by Salman et al. (2017, UK) reported the presence of HPV genome (42\%) in breast cancer patients, concluding that high expression level of E6 and E7 and their interactions with cellular factors can led to breast tumor development [40]. These results are consistent with our results and also with earlier studies on cervical cancer $[44,45]$. Other investigations have reported different prevalence of HPV in breast cancer patients as follows; 41.6\% (2015, Venezuela), 40\% (2013, Mexico) and 21\% (2008, Japan) [36, 46, 47]. Our result and other studies have been compared in Table 7 . It is noteworthy that despite using viral DNA detection method to show the presence of the virus, this does not demonstrate the active infection. [40]. Several studies have shown the expression of the HPV proteins in breast tissue is a reliable marker to detect the active infection. For instance, it has been demonstrated that the expression level of E7 in breast cancer tissue was higher than healthy controls and patients with early stages of cancer [40]. Therefore, we assessed the expression level of E6 and $E 7$ to evaluate the viral activity.

HPV 16 and 18 genotypes are considered as two of the most common virus genotypes that can be found in cancers worldwide $[36,47]$. Other types of HPV including 6, $11,33,35,39,45,51$ and 59 have been also detected in breast cancers patients [40, 46, 48]. For the first time, Yingyan $Y u$ et al. (2000, China) reported the detecting HPV-33 in $43.8 \%$ of their evaluated patients with breast

Table 5 Comparison expressions level of TGF- $\beta, I L-17, I L-6, I L-1, T N F-a, N F-K B, R O S, R N S, B R C A 1$ and BRCA2 in breast cancer, control samples, positive HPV, and negative HPV samples

\begin{tabular}{|c|c|c|c|c|c|c|c|c|}
\hline Expression level & $\begin{array}{l}\text { Breast Cancer } \\
(N=72)\end{array}$ & $\begin{array}{l}\text { Control } \\
(N=31)\end{array}$ & Fold Change & $\begin{array}{l}\text { Adjusted } \\
\text { P-value }\end{array}$ & $\begin{array}{l}\text { HPV positive } \\
(N=40)\end{array}$ & $\begin{array}{l}\text { HPV negative } \\
(N=63)\end{array}$ & $\begin{array}{l}\text { Fold } \\
\text { Change }\end{array}$ & $\begin{array}{l}\text { Adjustec } \\
P \text {-value }\end{array}$ \\
\hline TGF- $\beta$ & $12.40 \pm 9.11$ & $5.29 \pm 3.68$ & 2.34 & 0.0013 & $18.65 \pm 7.53$ & $4.94 \pm 3.06$ & 3.75 & 0.001 \\
\hline IL-17 & $12.61 \pm 9.46$ & $4.97 \pm 4.29$ & 2.54 & 0.0013 & $20.05 \pm 6.28$ & $4.13 \pm 3.33$ & 4.85 & 0.001 \\
\hline IL-6 & $9.32 \pm 7.27$ & $3.97 \pm 3.29$ & 2.35 & 0.0013 & $14.30 \pm 5.58$ & $3.52 \pm 3.22$ & 4.06 & 0.001 \\
\hline $\mid \mathrm{L}-1$ & $8.90 \pm 6.21$ & $6.10 \pm 4.48$ & 1.46 & 0.0103 & $14.65 \pm 5.06$ & $3.87 \pm 2.30$ & 3.78 & 0.001 \\
\hline TNF-a & $9.40 \pm 7.56$ & $4.77 \pm 3.28$ & 1.97 & 0.0013 & $15.83 \pm 6.33$ & $3.05 \pm 3.01$ & 5.19 & 0.001 \\
\hline$N F-k B$ & $9.26 \pm 7.67$ & $5.48 \pm 4.91$ & 1.69 & 0.0290 & $14.75 \pm 5.97$ & $3.92 \pm 3.51$ & 3.76 & 0.001 \\
\hline ROS & $10.08 \pm 8.87$ & $3.35 \pm 3.06$ & 3.01 & 0.0013 & $16.38 \pm 7.29$ & $2.78 \pm 2.47$ & 5.89 & $<0.001$ \\
\hline RNS & $11.32 \pm 9.84$ & $3.94 \pm 2.88$ & 2.87 & 0.0013 & $17.82 \pm 8.82$ & $3.56 \pm 2.83$ & 5.01 & $<0.001$ \\
\hline BRCA1 & $9.58 \pm 5.35$ & $14.45 \pm 4.58$ & 0.66 & 0.0013 & $8.32 \pm 4.43$ & $12.77 \pm 5.58$ & 0.65 & $<0.001$ \\
\hline BRCA2 & $7.23 \pm 3.84$ & $12.66 \pm 4.03$ & 0.57 & 0.0013 & $5.15 \pm 1.92$ & $11.22 \pm 3.79$ & 0.46 & $<0.001$ \\
\hline
\end{tabular}

* FDR correction for multiple comparisons by Benjamini-Hochberg method 
Table 6 Associations between expression level of TGF- $\beta, I L-17, I L-6, I L-1, T N F-a, N F-K B, R O S, R N S, B R C A 1$ and BRCA2 with breast cancer and presence of HPV

\begin{tabular}{lllll}
\hline $\begin{array}{l}\text { Expression } \\
\text { level }\end{array}$ & Breast Cancer & & Presence of HPV \\
\cline { 2 - 4 } & Correlation Coefficient & Adjusted $P$-value & \\
\hline TGF- $\beta$ & 0.608 & 0.0016 & 0.877 & $<0.001$ \\
IL-17 & 0.618 & 0.0087 & 0.953 & $<0.001$ \\
IL-6 & 0.464 & 0.0016 & 0.959 & $<0.001$ \\
IL-1 & 0.497 & 0.0410 & 0.949 & $<0.001$ \\
TNF-a & 0.602 & 0.0071 & 0.971 & $<0.001$ \\
NF-KB & 0.418 & 0.0155 & 0.953 & $<0.001$ \\
ROS & 0.613 & $<0.001$ & 0.958 & $<0.001$ \\
RNS & 0.633 & $<0.001$ & 0.956 & $<0.001$ \\
BRCA1 & 0.831 & $<0.001$ & 0.797 & $<0.001$ \\
BRCA2 & 0.736 & $<0.001$ & 0.952 & $<0.001$ \\
\hline FDR
\end{tabular}

* FDR correction for multiple comparisons by Benjamini-Hochberg method. Eta-squared considered as an effect size of correlation

cancer. However, they did not report the presence of HPV-16 and HPV-18 DNA in their cases [48]. In the current study, we reported the prevalence of HPV-33 to be $5.6 \%$ in breast cancer samples but not in any of healthy controls. There could be several hypotheses addressing this difference, prevalence and genotypes distribution of HPV, including geographical, sample size, sampling, and methodological differences [36, 49]. Among all the mentioned reasons, it seems that the main reason could be the difference in the geographical areas which may cause variety in the prevalence of HPV type distribution. Another important factor is the sensitivity of methods used to detect viral genome. For instance, the use of different primer sets may result in highest sensitivity and specificity. In the current study, two sets of primers were used for $L 1$ and E6/E7, since $L 1$ gene is frequently lost during HPV integration into the host genome [50]. Although different methods such as in situ hybridization (ISH) could be used for HPV DNA detection, but this method may not detect HPV DNA in some samples. Therefore, it has been suggested that the PCR can be more sensitive than ISH [49]. A study has been conducted to compare the sensitivity of PCR and ISH methods for the detection of HPV in patients with breast cancer. This investigation was considered since they used PCR method to show the presence of HPV DNA in $46 \%$ of breast cancer cases, while using ISH resulted in only one positive case [51]. Our results showed that in the group of HPV DNA positive patients, the ductal carcinoma was more frequent than other types of cancer $(N=16,45.7 \%)$. It was also accompanied with the lower incidence of mucinous carcinoma $(0 \%)$. Also, we showed that the highest HPV incidence was similar to the recent study investigating on the role of HPV in breast carcinogenesis in the UK. In contrast, the prevalence of HPVs DNA in lobular carcinoma was found to be the lowest [40].

The E2/E6 ratio was used to determine the physical status of HPV genome. When the ratio is equal to zero, larger than zero and smaller, equal to or higher than 1 , HPV genome is integrated, made up from both episomal and integrated forms and episomal form, respectively
A

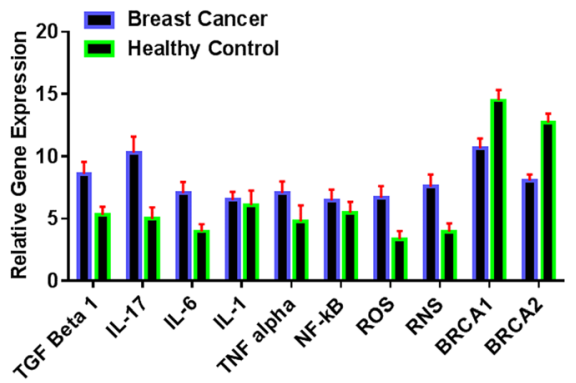

B

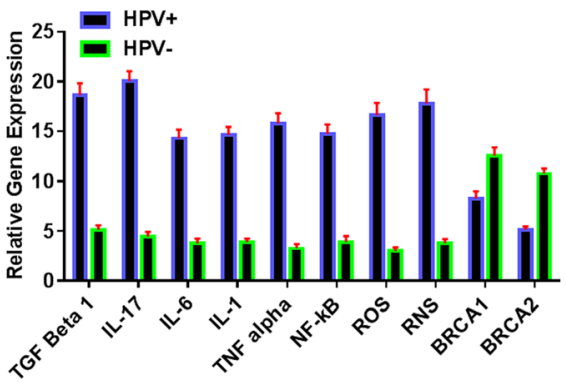

Fig. 1 Comparison of inflammation factors, BRCA1 and BRCA2 expression level: (a) in breast cancer with control, (b) in HPV positive with HPV negative samples 
Table 7 Evaluation of differences in prevalence of HPV infected breast cancer patients among different studies

\begin{tabular}{|c|c|c|c|c|}
\hline Study & Year/Country & $\mathrm{HPV}^{+}$patients & $\mathrm{HPV}^{+}$controls & Most prevalent HPV \\
\hline Current study & $2017 /$ Iran & $48.6 \%$ & $16.1 \%$ & HPV-18 (22.2\%) \\
\hline Islam et al. & 2017/India & $63.9 \%$ & $9.5 \%$ & HPV-16 (69\%) \\
\hline Salman et al. & 2017/UK & $42 \%$ & $17 \%$ & HPV-39 (20\%) \\
\hline Fernandes et al. & 2015/Venezuela & $41.6 \%$ & NA & HPV-51 (30.7\%) \\
\hline Herrera-Goepfert et al. & 2013/Mexico & $40 \%$ & NA & HPV-16 (87.5\%) \\
\hline Sigaroodi et al. & 2012/Iran & $25.9 \%$ & $2.4 \%$ & HPV-16 and 18 (both 25\%) \\
\hline Khan et al. & 2008/Japan & $21 \%$ & NA & HPV-16 (92\%) \\
\hline Yu et al. & 2000/China & $43.8 \%$ & NA & HPV-33 (43.8\%) \\
\hline
\end{tabular}

$[36,52]$. Previous studies have shown that physical status of HPV DNA in cervical cancer is considered as a marker of tumor development [52]. Khan et al. detected HPV DNA in $21 \%$ of evaluated breast cancer samples. They demonstrated that all the HPV genome was considered integrated into the host genome except for one case which was a mixed form [36]. Islam and colleagues reported a prevalence of $63.9 \%$ for HPV in patients with breast cancer, demonestirating that $87.5 \%$ of their patients with positive HPV had integrated genome and $4.2 \%$ were in episomal form [53]. In the present study, according to the E2/E6 ratio, $30(86 \%, P=0.006)$ and 5 (14\%) of HPV genomes were integrated and mixed form, respectively. Our results demonstrated that E2/E6 ratio was significantly different in the tumor types and stages. Most integration and mixed form were detected in ductal form of tumor and stages III and IV. Such high rate of integration is accompanying with tumor development because this finally leads to increasing the expression level of E6 and E7. This issue has already been proven in Cervical Cancer [40]. One of the limitations in our study was to use E2/E6 ratio for determination of physical status of HPV genome while Zhang et al. have demonstrated that $E 2 / E 6$ or $E 2 / E 7$ is less sensitive and predictive than $E 2 / E 6 E 7$ for determination of physical status of HPV genome in cervical cancer [54]. Therefore, in our study, the percentage of integrated HPV genomes was probably more than the percentage we reported. On the other hand, the multiple E1-L1/E6E7 ratio analysis needs four more PCR reactions than E2/E6E7 ratio analysis. Further studies is required to estimate the cost-effectiveness of this modification, which can be considered as a drawback. [54]. To the best of our knowledge, this is the first study reporting the physical status of HPV genome in breast cancer tissue in Middle East.

There are numerous distinct stages from the beginning of viral infection to the tumor development. For example, the progression of cervical tumors in patients infected by HPV are including these models: (1) HPV infection CIN 1, 2; (2) persistent HPV-infection, CIN 1, 2; (3) CIN 3; (4) cervical cancer. These stages are affected by different cofactors $[9,55]$. The role of HPV in initiation and development of breast cancer can be discussed from two aspects: (1) Direct role; interactions of viral proteins with key regulator proteins of the cell, (2) Indirect role; induction of inflammation.

Through targeting p53 and RB, oncoproteins of HPV such as E6 and E7 could disrupt the cell cycle, initiate malignant transformation and finally lead to tumor development [44]. This is inevitable since p53 and RB play crucial roles in controlling cell cycle and genome repair, and therefore interference and degradation of these proteins may lead to uncontrolled cellular proliferation and finally cancer. Herein, it was demonstrated that compared to controls, the expression levels of p53 and RB in cancer samples were decreased significantly $(P=0.001$ and $P=$ 0.033 respectively). Also, the expression levels of p53 and $\mathrm{RB}$ were compared between HPV positive and HPV negative patients diagnosed with breast cancer and it was showed that these levels were significantly reduced in HPV-positives breast cancer patients compared to HPV-negatives breast cancer patients (both $P<0.001$ ).

In the breast, as well as all other tissues, the BRCA1 and BRCA2 are expressed and involved in repair process of damaged DNA and any reduction or disruption of these two proteins could lead to cancer [56]. It has been shown that E6 and E7 proteins are able to interact with the BRCA1 (as the antagonists) and alter its activity. Moreover, BRCA1 interacts with RB and p53. This interaction is required for the $R B$ functioning in $G_{1}$ checkpoint of cell cycle. Also, BRCA1 acts as a co-activator of p53-mediated transcription [22]. Thus, HPV proteins (E6 and E7), may influence RB and p53 functions with indirect interference through BRCA1 pathway. In addition, we demonstrated that the expression levels of BRCA1 and BRCA2 were reduced in breast cancer tissue in comparison to the healthy controls (for both $P=$ 0.0013). Moreover, in HPV-positive breast cancer patients BRCA1 and BRCA2 were decreased (both $P<$ 0.001) compared to the HPV-negative group., suggesting 
that the role of HPV in breast cancers could be accomplished through interacting with these proteins.

Previous studies indicated that onco-viruses can be considered as a cause some types of cancers, but these infections seem to be just a prerequisite and viral infections can only provide some of the conditions which is necessary for carcinogenesis. Although, high-risk HPV types can lead to transform the human keratinocytes into cancer cells in vitro, without any additional factors [57], other co-factors such as chronic inflammation, environmental mutagens, and immunosuppression are required to carcinogenesis [58, 59]. Several epidemiological and clinical investigations have demonstrated that certain pathogens leading to persistent infection(s) are strongly correlated with cancer prevalence [60]. Persistent viral infections usually cause chronic inflammation through different factors such as induction of RONS production and producing mitogenic and angiogenic factors $[25,61]$. Inflammation could be considered as a double-edged sword; in the initial steps it is crucial for provoking anti-tumor responses by the immune system and after that, it favors tumor development by triggering angiogenesis [23]. Recent investigations indicated that the inflammation is the major hallmark for tumor progression $[60,62]$. Among the inflammatory cytokines, IL-1, TGF- $\beta$, and IL-6 are responsible for cancer cells proliferation and invasion through activation of NF-kB. TNF- $\alpha$, another inflammatory cytokine, is responsible in the main pathways of tumor inflammation. Moreover, it has been shown that TNF- $\alpha--N F-\kappa B$ axis is related to the invasiveness and malignant behavior of breast cancer cells. TNF- $\alpha$, IL- 1 , TGF- $\beta$, and IL- 6 are able to induce the expression of many angiogenic growth factors in tumor such as vascular endothelial growth factor (VEGF) [24]. Also, IL-17 is related to the cancer cell survival and invasion as well as regulation of angiogenesis [63]. The present study clearly showed that the expression of inflammatory factors including IL-1, IL-6, IL-17, TNF- $\alpha$, TGF- $\beta$, NF- $\kappa$ B and RONS in HPV-positive breast cancer patients were higher than HPV-negative breast cancer patients and healthy controls (Fig. 1 and Table 5). This indicated a significant role of inflammation in cancer induction among HPV infected patients with breast cancer. The increased inflammatory status caused by HPV may increase tumor development and tumor cells' survival as well as angiogenesis [22], and consequently this lead to cancer cells proliferation and tumor metastasis [23]. Taken together, it seems that the detected inflammation in these patients may be related to viral infection, persistent infection, and its proteins. Despite all the results of this study, the role of HPV in breast cancers is still questionable. To the best of our knowledge, this is the first study reporting the association between inflammation and $\mathrm{HPV}$ in breast cancer patients.

\section{Conclusion}

In the current study, HPV genome was detected in $48.6 \%$ of breast cancer samples among which most (82.8\%) were at stage II and III. Being infected with HPV as a risk factor could directly or indirectly interfere with certain cellular mechanisms which lead to tumorigenesis and cancer development. We demonstrated that HPV is associated with breast cancer development, although the role of HPV in breast cancers is still questionable and further research is required to investigate, in more detail, the role of HPV infection in breast cancer.

\section{Abbreviations \\ BAK: BCL2 antagonist/killer; BRCA: Breast and ovarian cancer susceptibility gene; Cl: Confidence interval; ELISA: Enzyme-linked immunosorbent assay; HPV: Human papilloma virus; IL: Interleukin; JNK/SAPK: c-Jun N-terminal kin- ase/stress-activated protein kinase; KIP: Kinesin-like protein; NF-KB: Nuclear factor KB; PCR: Polymerase chain reaction; RB: Retinoblastoma; RF: Risk factor; RONS: Reactive oxygen nitrogen species; RT-PCR: Real-time PCR; TGF- $\beta$ : Transforming growth factor $\beta$; TNF- $\alpha$ : Tumor necrosis factor $\alpha$; VEGF: Vascular endothelial growth factor}

\section{Acknowledgements}

The authors deeply acknowledge all the patients who contributed to this study. Also, authors are greatly thankful to the director and staff of Rasul-e Akram and Kashani Hospitals for their valuable helps.

\section{Funding}

This work was supported by Iran University of Medical Sciences (IUMS) by grant number 41554. The funding body had no role in the design of the study and collection, analysis, and interpretation of data and in writing the manuscript.

\section{Availability of data and materials \\ The datasets used and/or analyzed during the current study could become available through the corresponding author on reasonable request.}

\section{Authors' contributions}

$\mathrm{NK}, \mathrm{MM}$ and MP designed the project. AE, AG and AHN contributed to perform DNA and RNA extraction, PCR and Real time PCR. MM and SH contributed to perform Elisa. SM, AK and MM contributed to data analysis. All authors have read and approved the final manuscript.

\section{Ethics approval and consent to participate}

The study was approved by ethical committee of Shahrekord University of Medical Sciences, Shahrekord, Iran under the Ethics code of 125391 and the ethical Committee of Iran University of Medical Sciences 93-22311. Also, all subjects (or the person having the care and custody of the child) signed an informed consent form regarding the participation in the study and a consent for publication.

Consent for publication

Not applicable.

Competing interests

The authors declare that they have no competing interests.

\section{Publisher's Note}

Springer Nature remains neutral with regard to jurisdictional claims in published maps and institutional affiliations.

\section{Author details}

'Department of Internal Medicine, Faculty of Medicine, Iran University of Medical Sciences, Tehran, Iran. ${ }^{2}$ Department of Community Medicine, Faculty of Medicine, Alborz University of Medical Sciences, Tehran, Iran. ${ }^{3}$ Department of Biostatistics, Faculty of Medical Sciences, Tarbiat Modares University, Tehran, Iran. ${ }^{4}$ Department of Biology, Faculty of Science, Shahrekord 
University, Shahrekord, Iran. ${ }^{5}$ Department of Materials Science and Engineering, Sharif University of Technology, Tehran, Iran. ${ }^{6}$ Cancer Research Center, Kermanshah University of Medical Sciences, Kermanshah, Iran. ${ }^{7}$ Department of Mycobacteriology \& Pulmonary Research, Pasteur Institute of Iran, Tehran, Iran. ${ }^{8}$ Regenerative Medicine Research Center, Kermanshah University of Medical Sciences, Kermanshah, Iran. ${ }^{9}$ Department of Microbiology, Faculty of Medicine, Kermanshah University of Medical Sciences, Sorkheh-Ligeh Blvd, P. O. Box: 6716777816, Kermanshah, Iran.

Received: 1 November 2017 Accepted: 7 January 2019

\section{Published online: 14 January 2019}

\section{References}

1. Kroupis C, Markou A, Vourlidis N, Dionyssiou-Asteriou A, Lianidou ES Presence of high-risk human papillomavirus sequences in breast cancer tissues and association with histopathological characteristics. Clin Biochem. 2006;39(7):727-31

2. Bae J-M, Kim EH. Human papillomavirus infection and risk of breast cancer a meta-analysis of case-control studies. Infectious agents and cancer. 2016 11(1):14

3. Yu Y, Xiao C, Tan L, Wang Q, Li X, Feng Y. Cancer-associated fibroblasts induce epithelial-mesenchymal transition of breast cancer cells through paracrine TGF- $\beta$ signalling. Br J Cancer. 2014;110(3):724-32.

4. Parkin D, Bray F, Ferlay J, Pisani P. Cancer incidence, mortality and prevalence worldwide, GLOBOCAN 2002, American Cancer Society. Cancer J Clin. 2005:55:74-108

5. Parkin DM. The global health burden of infection-associated cancers in the year 2002. Int J Cancer. 2006;118(12):3030-44.

6. Goldszmid RS, Dzutsev A, Trinchieri G. Host immune response to infection and cancer: unexpected commonalities. Cell Host Microbe. 2014;15(3):295-305.

7. Park IH, Ko K, Joo J, Park B, Jung S-Y, Lee S, Kwon Y, Kang H-S, Lee ES, Lee KS. High volumetric breast density predicts risk for breast cancer in postmenopausal, but not premenopausal, Korean women. Ann Surg Oncol. 2014;21(13):4124-32.

8. Bae J-M. Two hypotheses of dense breasts and viral infection for explaining incidence of breast cancer by age group in Korean women. Epidemiology and health. 2014;36:e2014020.

9. Petry KU. HPV and cervical cancer. Scand J Clin Lab Invest. 2014;74(sup244): 59-62.

10. Schiffman M, Castle PE, Jeronimo J, Rodriguez AC, Wacholder S. Human papillomavirus and cervical cancer. Lancet. 2007;370(9590):890-907.

11. Di Lonardo A, Venuti A, Marcante ML. Human papillomavirus in breast cancer. Breast Cancer Res Treat. 1992;21(2):95-100.

12. Daudt C, da Silva FR, Streck AF, Weber MN, Mayer FQ, Cibulski SP, Canal CW. How many papillomavirus species can go undetected in papilloma lesions? Scientific reports 2016;6:1-7.

13. Kan C, lacopetta B, Lawson J, Whitaker N. Identification of human papillomavirus DNA gene sequences in human breast cancer. Br J Cancer. 2005:93(8):946-8

14. Sigaroodi A, Nadji SA, Naghshvar F, Nategh R, Emami H, Velayati AA. Human papillomavirus is associated with breast cancer in the north part of Iran. Scientific World Journal. 2012;2012:1-8.

15. Morshed K, Polz-Gruszka D, Szymański M, Polz-Dacewicz M. Human papillomavirus (HPV)-structure, epidemiology and pathogenesis. Otolaryngol Pol. 2014;68(5):213-9.

16. Zur Hausen H. Papillomaviruses and cancer: from basic studies to clinical application. Nat Rev Cancer. 2002;2(5):342-50.

17. Jackson S, Harwood C, Thomas M, Banks L, Storey A. Role of Bak in UVinduced apoptosis in skin cancer and abrogation by HPV E6 proteins. Genes Dev. 2000:14(23):3065-73.

18. Yim E-K, Park J-S. The role of HPV E6 and E7 oncoproteins in HPV-associated cervical carcinogenesis. Cancer Res Treat. 2005;37(6):319-24.

19. Fackenthal JD, Olopade Ol. Breast cancer risk associated with BRCA1 and BRCA2 in diverse populations. Nat Rev Cancer. 2007:7(12):937-48.

20. Rosen E, Fan S, Isaacs C. BRCA1 in hormonal carcinogenesis: basic and clinical research. Endocr Relat Cancer. 2005;12(3):533-48.

21. Santivasi W, Wang H, Wang T, Yang Q, Mo X, Brogi E, Haffty B, Chakravarthy A, Xia F. Association between cytosolic expression of BRCA1 and metastatic risk in breast cancer. Br J Cancer. 2015;113(3):453-9.
22. Zhang Y, Fan S, Meng Q, Ma Y, Katiyar P, Schlegel R, Rosen EM. BRCA1 interaction with human papillomavirus oncoproteins. J Biol Chem. 2005; 280(39):33165-77

23. Stone SC, Rossetti RAM, Lima AM, Lepique AP. HPV associated tumor cells control tumor microenvironment and leukocytosis in experimental models. Immunity, inflammation and disease. 2014;2(2):63-75.

24. Esquivel-Velázquez M, Ostoa-Saloma P, Palacios-Arreola MI, Nava-Castro KE, Castro Jl, Morales-Montor J. The role of cytokines in breast cancer development and progression. J Interf Cytokine Res. 2015;35(1):1-16.

25. Fernandes JV, Fernandes TAAM, de Azevedo JCV, Cobucci RNO, de Carvalho MGF, Andrade VS, De Araujo JMG. Link between chronic inflammation and human papillomavirus-induced carcinogenesis (review). Oncol Lett. 2015; 9(3):1015-26.

26. Nicolini A, Carpi A, Rossi G. Cytokines in breast cancer. Cytokine Growth Factor Rev. 2006:17(5):325-37.

27. Knüpfer H, Preiß R. Significance of interleukin-6 (IL-6) in breast cancer (review). Breast Cancer Res Treat. 2007;102(2):129-35.

28. Apte RN, Krelin Y, Song X, Dotan S, Recih E, Elkabets M, Carmi Y, Dvorkin T, White RM, Gayvoronsky L. Effects of micro-environment-and malignant cellderived interleukin-1 in carcinogenesis, tumour invasiveness and tumourhost interactions. Eur J Cancer. 2006:42(6):751-9.

29. Lewis AM, Varghese S, Xu H, Alexander HR. Interleukin-1 and cancer progression: the emerging role of interleukin-1 receptor antagonist as a novel therapeutic agent in cancer treatment. J Transl Med. 2006;4(1):48.

30. Karin M, Greten FR. NF-kB: linking inflammation and immunity to cance development and progression. Nat Rev Immunol. 2005;5(10):749-59.

31. Pacifico F, Leonardi A. Role of NF-KB in thyroid cancer. Mol Cell Endocrinol. 2010:321(1):29-35

32. Haklar G, Sayin-Özveri E, Yüksel M, Aktan AÖ, Yalçin AS. Different kinds of reactive oxygen and nitrogen species were detected in colon and breast tumors. Cancer Lett. 2001;165(2):219-24

33. Lu C, Heldt JM, Guille-Collignon M, Lemaître F, Jaouen G, Vessières A, Amatore C. Quantitative analyses of ROS and RNS production in breast cancer cell lines incubated with ferrocifens. ChemMedChem. 2014;9(6):1286-93.

34. De Marzo AM, Platz EA, Sutcliffe S, Xu J, Grönberg H, Drake CG, Nakai Y, Isaacs WB, Nelson WG. Inflammation in prostate carcinogenesis. Nat Rev Cancer. 2007;7(4):256-69.

35. Tavassoli FA, Devilee P. Pathology and genetics of tumours of the breast and female genital organs: larc; 2003.

36. Khan N, Castillo A, Koriyama C, Kijima Y, Umekita Y, Ohi Y, Higashi M, Sagara Y, Yoshinaka H, Tsuji T. Human papillomavirus detected in female breast carcinomas in Japan. Br J Cancer. 2008;99(3):408-14.

37. Jang M, Rhee J, Jang D-H, Kim SS. Gene expression profiles are altered in human papillomavirus-16 E6 D25E-expressing cell lines. Virol J. 2011;8(1):453.

38. Wang-Johanning F, Lu DW, Wang Y, Johnson MR, Johanning GL. Quantitation of human papillomavirus 16 E6 and E7 DNA and RNA in residual material from ThinPrep Papanicolaou tests using real-time polymerase chain reaction analysis. Cancer. 2002;94(8):2199-210.

39. Webster K, Parish J, Pandya M, Stern PL, Clarke AR, Gaston K. The human papillomavirus (HPV) 16 E2 protein induces apoptosis in the absence of other HPV proteins and via a p53-dependent pathway. J Biol Chem. 2000; 275(1):87-94.

40. Salman NA, Davies G, Majidy F, Shakir F, Akinrinade H, Perumal D, Ashrafi $\mathrm{GH}$. Association of High Risk Human Papillomavirus and Breast cancer: a UK based study. Sci Rep. 2017:7:43591.

41. Moghoofei M, Mostafaei S, Nesaei A, Etemadi A, Sadri Nahand J, Mirzaei H, Rashidi B, Babaei F, Khodabandehlou N. Epstein-Barr virus and thyroid cancer: The role of viral expressed proteins. J Cell Physiol. 2018;234(4):3790-99.

42. zur Hausen $\mathrm{H}$. Papillomaviruses in the causation of human cancers - a brief historical account. Virology. 2009;384(2):260-5.

43. Heng B, Glenn W, Ye Y, Tran B, Delprado W, Lutze-Mann L, Whitaker N, Lawson J. Human papilloma virus is associated with breast cancer. $\mathrm{Br}$ J Cancer. 2009;101(8):1345-50

44. Doorbar J. Molecular biology of human papillomavirus infection and cervical cancer. Clin Sci. 2006;110(5):525-41.

45. von Knebel Doeberitz M. New markers for cervical dysplasia to visualise the genomic chaos created by aberrant oncogenic papillomavirus infections. Eur J Cancer. 2002:38(17):2229-42.

46. Fernandes A, Bianchi G, Feltri AP, Pérez M, Correnti M. Presence of human papillomavirus in breast cancer and its association with prognostic factors. ecancermedicalscience. 2015;9. 
47. Herrera-Goepfert R, Vela-Chávez T, Carrillo-García A, Lizano-Soberón M, Amador-Molina A, Oñate-Ocaña LF, Hallmann RS-R. High-risk human papillomavirus (HPV) DNA sequences in metaplastic breast carcinomas of Mexican women. BMC Cancer. 2013;13(1):445.

48. Yu Y, Morimoto T, Sasa M, Okazaki K, Harada Y, Fujiwara T, Irie Y, Takahashi E-i, Tanigami A, Izumi K. Human papillomavirus type 33 DNA in breast cancer in Chinese. Breast Cancer. 2000;7(1):33-6.

49. Wang T, Chang P, Wang L, Yao Q, Guo W, Chen J, Yan T, Cao C. The role of human papillomavirus infection in breast cancer. Med Oncol. 2012;29(1):48-55.

50. Sattarahmady N, Tondro G, Gholchin M, Heli H. Gold nanoparticles biosensor of Brucella spp. genomic DNA: visual and spectrophotometric detections. Biochem Eng J. 2015;97:1-7.

51. Hennig EM, Suo Z, Thoresen S, Holm R, Kvinnsland S, Nesland JM. Human papillomavirus 16 in breast cancer of women treated for high grade cervical intraepithelial neoplasia (CIN III). Breast Cancer Res Treat. 1999;53(2):121-35.

52. Peitsaro $P$, Johansson $B$, Syrjänen $S$. Integrated human papillomavirus type 16 is frequently found in cervical cancer precursors as demonstrated by a novel quantitative real-time PCR technique. J Clin Microbiol. 2002;40(3):886-91.

53. Islam S, Dasgupta H, Roychowdhury A, Bhattacharya R, Mukherjee N, Roy A, Mandal GK, Alam N, Biswas J, Mandal S. Study of association and molecular analysis of human papillomavirus in breast cancer of Indian patients: clinical and prognostic implication. PLoS One. 2017;12(2)::0172760

54. Zhang R, He Y-F, Chen M, Chen C-M, Zhu Q-J, Lu H, Wei Z-H, Li F, Zhang X$X$ X X C-J. Diagnosis of 25 genotypes of human papillomaviruses for their physical statuses in cervical precancerous/cancerous lesions: a comparison of E2/E6E7 ratio-based vs. multiple E1-L1/E6E7 ratio-based detection techniques. J Transl Med. 2014;12(1):282.

55. Campos NG, Burger EA, Sy S, Sharma M, Schiffman M, Rodriguez AC, Hildesheim A, Herrero R, Kim JJ. An updated natural history model of cervical cancer: derivation of model parameters. Am J Epidemiol. 2014; 180(5):545-55.

56. Friedenson B. The BRCA1/2 pathway prevents hematologic cancers in addition to breast and ovarian cancers. BMC Cancer. 2007;7(1):152

57. Knipe D, Howley P, Griffin D, Lamb R, Martin M, Roizman B, Straus S. Fields Virology. Vol I+ II. Lippincott: Williams \& Wilkins; 2013.

58. zur Hausen $\mathrm{H}$. The search for infectious causes of human cancers: where and why (Nobel lecture). Angew Chem Int Ed. 2009:48(32):5798-808.

59. Bouvard V, Baan R, Straif K, Grosse Y, Secretan B, El Ghissassi F, BenbrahimTallaa L, Guha N, Freeman C, Galichet L. A review of human carcinogens_Part B: biological agents. In.: Elsevier; 2009;10(4):321-2.

60. Coussens LM, Werb Z. Inflammation and cancer. Nature. 2002; 420(6917):860-7.

61. Mesri EA, Feitelson MA, Munger K. Human viral oncogenesis: a cancer hallmarks analysis. Cell Host Microbe. 2014;15(3):266-82.

62. Etemadi A, Mostafaei S, Yari K, Ghasemi A, Minaei Chenar H, Moghoofei M. Detection and a possible link between parvovirus B19 and thyroid cancer. Tumor Biol. 2017;39(6):1010428317703634.

63. Welte T, Zhang XH-F. Interleukin-17 could promote breast cancer progression at several stages of the disease. Mediators Inflamm. 2015;2015:1-6.

Ready to submit your research? Choose BMC and benefit from:

- fast, convenient online submission

- thorough peer review by experienced researchers in your field

- rapid publication on acceptance

- support for research data, including large and complex data types

- gold Open Access which fosters wider collaboration and increased citations

- maximum visibility for your research: over $100 \mathrm{M}$ website views per year

At $\mathrm{BMC}$, research is always in progress.

Learn more biomedcentral.com/submissions 